\title{
BMJ Open Mood disturbance and depression in Arab women following hospitalisation from acute cardiac conditions: a cross-sectional study from Qatar
}

\author{
Tam Truong Donnelly, ${ }^{1}$ Jassim Mohd Al Suwaidi, ${ }^{2}$ Awad Al-Qahtani, ${ }^{2}$ Nidal Asaad, ${ }^{2}$
} Tak Fung, ${ }^{3}$ Rajvir Singh, ${ }^{4}$ Najlaa Abdul Qader ${ }^{5}$

To cite: Donnelly TT, Al Suwaidi JM, Al-Qahtani A, et al. Mood disturbance and depression in Arab women following hospitalisation from acute cardiac conditions: a cross-sectional study from Qatar. BMJ Open 2016;6: e011873. doi:10.1136/ bmjopen-2016-011873

- Prepublication history for this paper is available online. To view these files please visit the journal online (http://dx.doi.org/10.1136/ bmjopen-2016-011873).

Received 11 March 2016 Revised 29 April 2016 Accepted 16 June 2016

CrossMark

\section{${ }^{1}$ Faculty of Nursing and Medicine, University of Calgary, Calgary, Alberta, Canada \\ ${ }^{2}$ Department of Adult Cardiology, Hamad Medical Corporation, Hamad General Hospital, Doha, Qatar ${ }^{3}$ University of Calgary, Math/ Information Technology, Calgary, Alberta, Canada ${ }^{4}$ Hamad Medical Corporation, Hamad General Hospital, Research Center/Adult Cardiology, Doha, Qatar ${ }^{5}$ Department of Psychiatry, Hamad Medical Corporation, Hamad General Hospital, Doha, Qatar}

Correspondence to Dr Tam Truong Donnelly; tdonnell@ucalgary.ca

\section{ABSTRACT \\ Objectives: Depression is associated with increased morbidity and mortality rates among cardiovascular patients. Depressed patients have three times higher risk of death than those who are not. We sought to determine the presence of depressive symptoms, and whether gender and age are associated with depression among Arab patients hospitalised with cardiac conditions in a Middle Eastern country.}

Setting: Using a non-probability convenient sampling technique, a cross-sectional survey was conducted with 1000 Arab patients $\geq 20$ years who were admitted to cardiology units between 2013 and 2014 at the Heart Hospital in Qatar. Patients were interviewed 3 days after admission following the cardiac event. Surveys included demographic and clinical characteristics, and the Arabic version of the Beck Depression Inventory Second Edition (BDI-II). Depression was assessed by BDI-II clinical classification scale.

Results: $15 \%$ of the patients had mild mood disturbance and $5 \%$ had symptoms of clinical depression. Twice as many females than males suffered from mild mood disturbance and clinical depression symptoms, the majority of females were in the age group 50 years and above, whereas males were in the age group $40-49$ years. $\chi^{2}$ Tests and multivariate logistic regression analyses indicated that gender and age were statistically significantly related to depression ( $p<0.001$ for all).

Conclusions: Older Arab women are more likely to develop mood disturbance and depression after being hospitalised with acute cardiac condition. Gender and age differences approach, and routine screening for depression should be conducted with all cardiovascular patients, especially for females in the older age groups. Mental health counselling should be available for all cardiovascular patients who exhibit depressive symptoms.

\section{INTRODUCTION}

Cardiovascular diseases (CVD) are the leading causes of death globally, and incidences of CVDs are increasing in the developing

\section{Strengths and limitations of this study}

- Depression is associated with increased morbidity and mortality rates among cardiovascular patients.

- The information reported in this paper will increase healthcare providers and researchers' awareness of the presence of depression, and its association with gender and age among Arab patients hospitalised with cardiac conditions in Qatar.

- It will help with the promotion of early detection and treatment for depression not only for Arab populations in Qatar, but also for patients of similar ethnocultural backgrounds in the Middle East region and worldwide.

- Non-probability convenience sampling limits the ability to generalise results from this study.

- Even though Beck Depression Inventory Second Edition has high reliability and validity, it might not accurately assess/identify depressive symptoms among Arabic population.

Middle Eastern (ME) countries. ${ }^{1-3}$ It is anticipated that from 1990 to 2020, the mortality rate from ischaemic heart disease in the Middle East will increase by $146 \%$ in females and $174 \%$ in males. ${ }^{1}$ Depression has been identified as predictive of both developing cardiovascular disease, and adverse outcomes among patients with existing cardiac disease. ${ }^{45}$ Studies show that depression is associated with increased morbidity and mortality rates among cardiovascular patients. ${ }^{4} 5$ Depressed patients have a 2.6-fold increase in cardiovascular-related mortality, and an almost 2.0-fold increase in new cardiovascular events. ${ }^{6}$ Early detection of, and intervention for, depression among cardiovascular patients can reduce cardiovascular morbidity and mortality, and save healthcare costs. Although there is a vast amount of information and studies 
regarding depression and its treatment among cardiovascular patients in the North American and European countries, depression and its management among Arab cardiovascular patients in ME region are not well understood. The objective of this study was to gain information about the prevalence of depression or mood disturbances, and to find ways to effectively manage depression by identifying factors associated with depression among Arab cardiovascular (CV) patients. ${ }^{7}$ In this paper, we report the presence of depression, and the association of gender and age with depression among Arab patients hospitalised with cardiac conditions in Qatar. Situated on the Gulf coast of the Arabian Peninsula, with a population of nearly 2 million, the State of Qatar ${ }^{8}$ has the world's fastest growing economy (19.4\% in 2010) and the highest gross domestic product per capita due to its abundant oil and natural gas revenues.

\section{METHODS}

Using a non-probability convenient sampling technique, self-identified Arabic speaking adult patients, 20 years and above, who were admitted with confirmed diagnosis of CVD/CAD to one of four cardiology units (chest pain unit, CCU, two Cardiology Floor units) between 2013 and 2014 at the Heart Hospital in Qatar were invited to participate in this cross-sectional survey by the highly trained research assistants fluent in English and Arabic. Patients were approached 3 days after admission, and interviewed when in stable condition. Survey questionnaires included demographic and clinical characteristics, history of mental health, cardiovascular disease risk factors and the self-reported Beck Depression Inventory Second Edition (BDI-II)-a 21-item self-report instrument rated on a four-point scale (0-3). The BDI-II has been highly recommended as a standard tool for assessment of early depression in hospitalised cardiac patients. ${ }^{9}$ BDI-II has been translated into Arabic, and tested for its reliability and validity in four Arab countries which were Egypt, Saudi Arabia, Kuwait and Lebanon. ${ }^{10}$ Furthermore, BDI-II instrument has been used as a tool for assessment of depression among inpatients at the General Hospital, Department of Psychiatry, Qatar, and was available for use in the survey. A factor analysis was performed with varimax rotation.

Prior to conducting the full-scale survey, the questionnaire was field tested with 30 participants (age 20 years and above); data collected from these participants were not included in the full survey. Based on the results of the field tested study, the data collection protocol and the survey instruments were refined by the research team members, expert cardiologists and psychologist for clarity and comprehensiveness. Depression was assessed and categorised according to BDI-II clinical classification scale: normal $\leq 10$, mild $11-16$ and depressed $\geq 17$. Patients who scored $\geq 17$ on the BDI-II (suggesting symptoms of clinical depression) were offered psychiatric assistance.

Data analyses were conducted by two senior biostatisticians using SPSS V.20. Descriptive statistics analyses (mean, SD for interval variables, and frequency with percentages for categorical variables) were performed for the study variables, where appropriate. $\chi^{2}$ Tests were applied to test for associations between sociodemographic factors and dependent variable (clinical classification of BDI-II scores-ie, normal $\leq 10$, mild 11-16, depressed $\geq 17$ ). Multicollinearity testing was performed before introducing independent variables into the multivariate analysis. Simultaneous multivariate ordinal logistic regression analyses were performed to further assess the association of preselected sociodemographic factors with the dependent variable (clinical classification of BDI-II scores-ie, normal $\leq 10$, mild 11-16, depressed $\geq 17$ ). All statistical tests were two-sided with significance established at an $\alpha$ of 0.05 levels. ${ }^{11}$ Owing to ordinal nature of depression which is measured by BDI-II ( $1=$ normal, $2=$ mild mood disturbance, $3=$ clinical depression), ordinal logistic regression analysis was performed. The test of parallel regression assumption for ordinal logistic regression was satisfied $\left(\chi^{2}(46)=29.28, p=0.974\right)$, which indicates that it is valid to use ordinal logistic regression in our analysis.

Written informed consent was waived, but verbal consent to participate in the study was obtained from each participant. Although the information obtained from the study participants was not de-identified, participants were assured that all information would be confidential. No incentive was given to participants of the study.

\section{RESULTS}

\section{Selected demographic characteristics of participants}

One thousand and twenty $(n=1020)$ patients who met the study's inclusion criteria were invited to participate in the study, of which 1000 patients participated in a $30 \mathrm{~min}$ face-to-face interview (response rate 98\%). Almost half of the study's participants were Qatari nationals (male 42\%; female 54\%). Citizens of the Levant countries (Syria, Lebanon, Palestine, Jordan), and North African countries (Egypt, Libya, Tunisia, Algeria, Morocco) constituted $20 \%$ and $18 \%$ of the participants, respectively. The rest of participants were from the Gulf Cooperation Council (GCC) and other countries.

Participants included 688 (69\%) males and 312 (31\%) females, and were between the ages of 20 and 92 years $(\mathrm{M}=58.2$ years, $\mathrm{SD}=12.7, \mathrm{n}=1000)$. Sixty-one per cent of female participants and $45 \%$ of male participants were over the age of 60 years. In the younger age group of 40 49 years there were twice as many male $(18 \%)$ than female $(9 \%)$ patients. The majority of the participants (74\% males and $81 \%$ females) had resided in Qatar for more than 10 years. Almost all participants were Muslim, with $\sim 50 \%$ regarding themselves as being 'active' in the 
practice of their religion. The majority of male participants were married $(90 \%)$, and $10 \%$ were without a spouse. However, among the female participants, $48 \%$ were married while $52 \%$ were without a spouse (table 1 ).

Many of these patients had multiple diagnoses of cardiovascular problems at the current hospital admission. Almost half of the patients had coronary artery disease (CAD; 54\%) and acute coronary syndrome (46\%); $29 \%$ also had heart failure, and $28 \%$ had acute myocardial infarction.

\section{Prevalence of depression among study's participants}

Compared to studies from the Middle East region which reported incidences of depression ranging from as low as $4.5 \%$ to as high as $66 \%$ among patients with CVD and

\begin{tabular}{|c|c|c|}
\hline Variables & $\begin{array}{l}\text { Male } \\
(n=688)\end{array}$ & $\begin{array}{l}\text { Female } \\
(n=312)\end{array}$ \\
\hline \multicolumn{3}{|l|}{ Age (years; $n=1000$ ) } \\
\hline 20-39 & $62(9 \%)$ & $18(6 \%)$ \\
\hline $40-49$ & $121(18 \%)$ & 27 (9\%) \\
\hline $50-59$ & $198(29 \%)$ & $77(25 \%)$ \\
\hline $60-69$ & $176(26 \%)$ & $115(37 \%)$ \\
\hline $70+$ & $131(19 \%)$ & $75(24 \%)$ \\
\hline \multicolumn{3}{|l|}{ Nationality $(n=1000)$} \\
\hline Qatari & $286(42 \%)$ & 169 (54\%) \\
\hline Levant & $140(20 \%)$ & $62(20 \%)$ \\
\hline North Africa & $143(21 \%)$ & $29(9 \%)$ \\
\hline Other GCC & $38(6 \%)$ & $23(7 \%)$ \\
\hline Other & $81(12 \%)$ & $29(9 \%)$ \\
\hline \multicolumn{3}{|c|}{ Years of residence in Qatar $(n=989)$} \\
\hline$\leq 5$ & $127(19 \%)$ & $53(17 \%)$ \\
\hline $6-10$ & $49(7 \%)$ & $7(2 \%)$ \\
\hline$>10$ & $504(74 \%)$ & $249(81 \%)$ \\
\hline \multicolumn{3}{|l|}{ Religion $(n=1000)$} \\
\hline Muslim & $674(98 \%)$ & $311(99.7 \%)$ \\
\hline Other & $14(2 \%)$ & $1(0.3 \%)$ \\
\hline \multicolumn{3}{|l|}{ Religion practice $(\mathrm{n}=995)$} \\
\hline Active & $278(41 \%)$ & $182(59 \%)$ \\
\hline Somewhat active & $347(51 \%)$ & $116(37 \%)$ \\
\hline Not active & $59(8 \%)$ & $13(4 \%)$ \\
\hline \multicolumn{3}{|l|}{ Marital status $(n=1000)$} \\
\hline Single & $40(6 \%)$ & $12(4 \%)$ \\
\hline Married & $619(90 \%)$ & $151(48 \%)$ \\
\hline Divorced/separated/widowed & $29(4 \%)$ & 149 (48\%) \\
\hline \multicolumn{3}{|l|}{ Patient education $(n=1000)$} \\
\hline No school & $91(13 \%)$ & $126(40 \%)$ \\
\hline Primary/junior School & $173(25 \%)$ & $98(31 \%)$ \\
\hline High/trade school & $158(23 \%)$ & $50(16 \%)$ \\
\hline University/above & $266(39 \%)$ & $38(12 \%)$ \\
\hline \multicolumn{3}{|l|}{ Patient occupation $(n=1000)$} \\
\hline Unemployed/retired/student & $264(38 \%)$ & $38(12 \%)$ \\
\hline Home-maker & 0 & $251(80 \%)$ \\
\hline Self-employed & $56(8 \%)$ & $1(0.3 \%)$ \\
\hline Unskilled worker & $39(6 \%)$ & 0 \\
\hline Skilled worker & $329(48 \%)$ & $22(7 \%)$ \\
\hline
\end{tabular}

chronic illness, ${ }^{7}$ in this study, the overall mean of BDI-II score was $6.5(\mathrm{SD}=6.3)$ of which $20 \%$ of the participants scored more than 10 on the BDI-II, indicating the presence of at least a mild mood disturbance to extreme depression. Almost twice as many female $(30 \%, \mathrm{n}=312)$ than male $(16 \%, \mathrm{n}=688)$ patients reported a BDI-II score of $\geq 11$, indicating symptoms of mild mood disturbance (11-16) and clinical depression $(\geq 17)$. Reliability analysis was performed on BDI-II-21 items, and this yielded a Cronbach's $\alpha$ of 0.81 . Furthermore, 23\% of the female participants considered themselves depressed as opposed to $15 \%$ of the males who felt the same. Less than $10 \%$ of both male and female patients $(\mathrm{n}=1000)$ had a history of depression. Of the 63 patients who reported the number of years they had been diagnosed with depression, $51 \%$ males and 29\% females had been diagnosed with depression for 5 years or less while $49 \%$ males and $71 \%$ females had been diagnosed with depression for more than 5 years. Among the patients who were assessed as having mood disturbance $(\mathrm{n}=144)$ and symptoms of depression $(n=58), 39$ patients reported taking antidepression medication. While the majority of patients were not taking antidepressant medication, the proportion of female participants $(3 \%)$ who were taking antidepressants was twice that for males $(1 \%)$ (table 2$)$.

\section{Association between gender, age and depression}

Univariate and $\chi^{2}$ analyses indicated that dependent factors (clinical classification of BDI-II scores-ie, normal $\leq 10$, mild $11-16$, depressed $\geq 17$ ) were statistically significantly related to gender $\left(\chi^{2}(2, \mathrm{~N}=1000)=26.56\right.$, $\mathrm{p}<0.001)$ and age $\left(\chi^{2} \quad(8, \mathrm{~N}=1000)=20.15, \quad \mathrm{p}=0.01\right)$ among the study's participants.

Table 2 Self-reported prevalence of depression

\begin{tabular}{|c|c|c|}
\hline Variables & $\begin{array}{l}\text { Male } \\
\mathrm{n}=688(69 \%)\end{array}$ & $\begin{array}{l}\text { Female } \\
\mathrm{n}=312(31 \%)\end{array}$ \\
\hline \multicolumn{3}{|c|}{ BDI-II depression category $(n=1000)$} \\
\hline Normal & $579(84 \%)$ & $219(70 \%)$ \\
\hline Mild mood disturbance & $80(12 \%)$ & $64(21 \%)$ \\
\hline Clinical depression & $29(4 \%)$ & $29(9 \%)$ \\
\hline \multicolumn{3}{|c|}{ Patient considers him(her)self depressed $(n=1000)$} \\
\hline No & $585(85 \%)$ & $240(77 \%)$ \\
\hline Yes & $103(15 \%)$ & $72(23 \%)$ \\
\hline \multicolumn{3}{|c|}{ History of depression $(n=1000)$} \\
\hline No & $643(93 \%)$ & $286(92 \%)$ \\
\hline Yes & $45(7 \%)$ & $26(8 \%)$ \\
\hline \multicolumn{3}{|c|}{ Years diagnosed with depression $(n=63)$} \\
\hline$\leq 5$ & $20(51 \%)$ & $7(29 \%)$ \\
\hline$>5$ & $19(49 \%)$ & $17(71 \%)$ \\
\hline \multicolumn{3}{|c|}{ Family members with depression $(n=999)$} \\
\hline No & 639 (93\%) & 284 (91\%) \\
\hline Yes & $49(7 \%)$ & 27 (9\%) \\
\hline \multicolumn{3}{|c|}{$\begin{array}{l}\text { Patient taking depression medication at the time of } \\
\text { interview }(n=1000)\end{array}$} \\
\hline No & 680 (99\%) & 303 (97\%) \\
\hline Yes & $8(1 \%)$ & $9(3 \%)$ \\
\hline
\end{tabular}


We further investigated the association between sociodemographic variables and gender broken down by three depression outcomes. Table 3 shows that male patients with mild mood disturbance were predominantly from the age groups of 40-49 (26\%), 50-59 (26\%) and 60-69 years (29\%) whereas females were from the age groups of 50-59 $(30 \%)$ and $60-69$ years $(39 \%)$. The majority of male patients with clinical depression were younger, in the age group 40-49 years $(41 \%)$, whereas females were in the older age groups of 50 years and older.

Many male patients with mild mood disturbance were highly educated $(47.5 \%)$ and most of them were skilled workers $(64.3 \%)$. On the other hand, the majority of female patients with mild mood disturbance were homemakers (74.6\%), and only $17.2 \%$ of them had university level of education. Male patients with clinical depression were also highly educated (52\%) and more than half of them were unemployed/retired $(60 \%)$. Female patients with clinical depression who had no schooling were $48 \%$, and most of them were home-makers $(82 \%)$.

Gender was statistically significantly related to all selected sociodemographic variables for each depression category except nationality for clinical depression group.

As we have previously mentioned, the test of parallel regression assumption for ordinal logistic regression was satisfied $\left(\chi^{2}(46)=29.28, p=0.974\right)$ which allowed us to use ordinal logistic regression in our model. Table 4 reports selected independent variables that might predict depression among participants.

Data analysis indicated that female participants had almost three times the odds of having depressive symptoms than male participants. Participants who were not Qatari citizen have higher depression odds compared to a Qatari citizen. Participant citizens of Levant countries (Syria, Lebanon, Palestine and Jordan) in the 20-39 and $50-59$ years age groups or having family history of depression were twice as likely to experience depressive symptoms than those who were not. Although more female participants in the older age group of 50 years and older were assessed as having mild mood disturbance and clinical depression; participants between the ages of 40-49 years had two to four times the odds of experiencing depression than those who were not. As expected, participants with history of depression had the highest odds of having depression after a cardiac event. Even though monthly income is not found as a predictor of depression $\left(\chi^{2}(5)=4.630, p=0.463\right)$ although controlling for the other socioeconomic factors, participants who perceived they were having financial stress and less financial support had twice the odds of having depressive symptoms than those who were not.

\section{DISCUSSION}

The results of our study indicate that $20 \%$ of the 1000 patients with confirmed CVD diagnosis experienced mild to extreme depression. This is lower than what has been reported in similar studies on Caucasian populations which suggest that $20-45 \%$ of cardiac patients suffered clinically depressive symptoms. ${ }^{12-14}$ As previously mentioned, compared to studies from the Middle East region which reported incidences of depression among patients with CVD and chronic illness ranging from $4.5 \%$ to $66 \%,{ }^{7}$ our survey indicates $80 \%$ of the patients had no depressive symptoms, $15 \%$ of the patients had mild mood disturbance and $5 \%$ had symptoms of clinical depression as assessed by the BDI-II. However, it is important to note that $17 \%$ of participants considered themselves as 'depressed'. It is possible that false negative occurs when the test of BDI-II reports a negative result for a patient who actually has depression. Despite that BDI-II has high reliability and validity, it has been pointed out that BDI-II has good sensitivity, but low specificity. ${ }^{15}$ Thus it is important that mental health services/counselling be available and offered to patients who consider themselves as 'depressed'.

Concurrent with other studies from the Middle East region which show significantly greater Arab females suffered from depressive symptoms compared to male counterparts, ${ }^{16}{ }^{17}$ our study found that almost twice as many female patients than male patients were assessed as having mild mood disturbance and clinical depression. It has been suggested that gender inequality, including limited opportunities for education and employment, early and arranged marriages, conservative attitudes towards sexuality and financial stress contributed to psychological risk among Arab women. ${ }^{17} 18$ Thus Arab female cardiac patients have increased risk of being depressed. Depression will significantly impact their disease prognosis, outcomes and quality of life.

Findings from a recent study indicated half of the hypertensive patients with clinical depression were in a younger age group of 40-59 years old. ${ }^{19}$ Evidence has also suggested that depression is most likely to affect young and middle-aged patients in the age bracket of $35-50$ years, and is less prevalent in patients aged 65 years and older; ${ }^{19}{ }^{20}$ however, it is important to note that the prevalence of CVD increases with age. ${ }^{19}{ }^{21}$ Our study shows that $61 \%$ of patients suffering from mild mood disturbance were aged between 50-69 years while almost half of the patients with clinical depression were younger, aged between $40-59$ years. We anticipate that socioeconomic factors and financial stress might be a risk factor for depression among younger working age group. ${ }^{11}$ In line with Ossola $e t a l \mathrm{~s}^{22}$ study which partly confirms the risk of depression in the late life of the general population, our data also indicated that for both mild mood disturbance and clinical depression, more females tended to be 60 years and older as compared to the male patients.

As part of the study's protocol, patients who scored $\geq 17$ on the BDI-II (suggesting symptoms of clinical depression) were offered psychiatric assistance. Of these patients, approximately half of both male and female patients refused psychiatric assistance. It is important to note that of those patients who refused psychiatric 


\begin{tabular}{|c|c|c|c|c|c|c|c|c|c|}
\hline \multirow[b]{2}{*}{ Variables } & \multicolumn{3}{|c|}{ Normal (0-10) } & \multicolumn{3}{|c|}{ Mild mood disturbance (11-16) } & \multicolumn{3}{|c|}{ Clinical depression $(\geq 17)$} \\
\hline & $\begin{array}{l}\text { Male } \\
\mathrm{N}=579\end{array}$ & $\begin{array}{l}\text { Female } \\
N=219\end{array}$ & p Value & $\begin{array}{l}\text { Male } \\
\mathrm{N}=80\end{array}$ & $\begin{array}{l}\text { Female } \\
\mathrm{N}=64\end{array}$ & p Value & $\begin{array}{l}\text { Male } \\
\mathrm{N}=29\end{array}$ & $\begin{array}{l}\text { Female } \\
\mathrm{N}=29\end{array}$ & p Value \\
\hline \multicolumn{10}{|l|}{ Nationality } \\
\hline Qatari & $251(43.4)$ & $122(55.7)$ & $\chi^{2}(4, N=798)=20.8$ & $20(25)$ & $34(53.1)$ & $\chi^{2}(4, N=144)=12.07$ & $15(51.7)$ & $13(44.8)$ & $\chi^{2}(4, N=58)$ \\
\hline Other GCC & $32(5.5)$ & $18(8.2)$ & $\mathrm{p}<0.01^{*}$ & $5(6.2)$ & $3(4.7)$ & $p=0.02^{*}$ & $1(3.4)$ & $2(6.9)$ & $=6.3, p=0.18$ \\
\hline Levant & $109(18.8)$ & $38(17.4)$ & & $26(32.5)$ & $13(20.3)$ & & $5(17.2)$ & $11(37.9)$ & \\
\hline North Africa & $116(20)$ & $18(8.2)$ & & $21(26.2)$ & $10(15.6)$ & & $6(20.7)$ & $1(3.4)$ & \\
\hline Other & 71 (12.3) & $23(10.5)$ & & $8(10)$ & $4(6.2)$ & & $2(6.9)$ & $2(6.9)$ & \\
\hline \multicolumn{10}{|l|}{ Age (years) } \\
\hline $20-39$ & $50(8.6)$ & $10(4.6)$ & $\chi^{2}(4, N=798)=18.4$ & $8(10)$ & $2(3.1)$ & $\chi^{2}(4, N=144)=11.8$ & $4(13.8)$ & $6(20.7)$ & $\chi^{2}(4, N=58)=14.9$ \\
\hline $40-49$ & 88 (15.2) & $20(9.1)$ & $\mathrm{p}<0.01^{*}$ & $21(26.2)$ & $6(9.4)$ & $\mathrm{p}=0.02^{*}$ & $12(41.4)$ & $1(3.4)$ & $\mathrm{p}<0.01^{*}$ \\
\hline $50-59$ & $169(29.2)$ & $51(23.3)$ & & $21(26.2)$ & $19(29.7)$ & & $8(27.6)$ & $7(24.1)$ & \\
\hline $60-69$ & $151(26.1)$ & $82(37.4)$ & & $23(28.8)$ & $25(39.1)$ & & $2(6.9)$ & $8(27.6)$ & \\
\hline $70+$ & $121(20.9)$ & $56(25.6)$ & & $7(8.8)$ & $12(18.8)$ & & $3(10.3)$ & $7(24.1)$ & \\
\hline \multicolumn{10}{|l|}{ Patient education } \\
\hline No school & $84(14.5)$ & $89(40.6)$ & $\chi^{2}(3, \mathrm{~N}=798)=90$ & $5(6.2)$ & $23(35.9)$ & $\chi^{2}(3, N=144)=27$ & $2(6.9)$ & $14(48.3)$ & $\chi^{2}(3, N=58)=17.9$ \\
\hline Primary/junior school & $146(25.2)$ & $68(31.1)$ & $p<0.01^{*}$ & $19(23.8)$ & 20 (31.2) & $p<0.01^{*}$ & $8(27.6)$ & $10(34.5)$ & $p<0.01^{\star}$ \\
\hline High/trade school & $136(23.5)$ & $38(17.4)$ & & $18(22.5)$ & $10(15.6)$ & & $4(13.8)$ & $2(6.9)$ & \\
\hline University/above & $213(36.8)$ & $24(11)$ & & 38 (47.5) & $11(17.2)$ & & $15(51.7)$ & $3(10.3)$ & \\
\hline \multicolumn{10}{|l|}{ Patient occupation } \\
\hline Unemployed/retired/student & $227(45.1)$ & $23(10.5)$ & $\chi^{2}(2, N=722)=551.6$ & $25(35.7)$ & $13(20.6)$ & $\chi^{2}(2, N=133)=87.4$ & $12(60.0)$ & $2(6.9)$ & $c^{2}(2, N=49)=32.87$ \\
\hline Home-maker & $0(0)$ & $180(82.2)$ & $\mathrm{p}<0.001^{*}$ & $0(0)$ & $47(74.6)$ & $p<0.001^{*}$ & $0(0)$ & $24(82.8)$ & $\mathrm{p}<0.001^{*}$ \\
\hline Skilled worker & $276(54.9)$ & $16(7.3)$ & & $45(54.3)$ & $3(4.8)$ & & $8(40.0)$ & $3(10.3)$ & \\
\hline \multicolumn{10}{|l|}{ Patient employment-fulltime } \\
\hline No & $273(47.2)$ & $206(94.1)$ & $\chi^{2}(1, N=798)=145$ & $31(38.8)$ & $62(96.9)$ & $\chi^{2}(1, N=144)=50.9$ & $1(51.7)$ & $26(89.7)$ & $\chi^{2}(1, N=58)=10.1$ \\
\hline Yes & $306(52.8)$ & $13(5.9)$ & $\mathrm{p}<0.01^{*}$ & $49(61.2)$ & $2(3.1)$ & $\mathrm{p}<0.01^{\star}$ & $14(48.3)$ & $3(10.3)$ & $\mathrm{p}=0.02^{*}$ \\
\hline
\end{tabular}


Table 4 Association between selected significant factors and depression

\begin{tabular}{|c|c|c|c|}
\hline $\begin{array}{l}\text { Predictors of depression } \\
\text { (1=normal, } 2=\text { mild, } 3=\text { severe) }\end{array}$ & $\begin{array}{l}\text { Test statistics and associated } \\
\text { degree of freedom }\end{array}$ & Adjusted OR (95\% Cl) & p Value \\
\hline Female & $\chi^{2}(1)=4.18, p=0.041$ & 2.75 (1.05 to 7.24$)$ & 0.041 \\
\hline Age group & $\chi^{2}(4)=11.10, p=0.026$ & & \\
\hline $20-39$ & & $2.16(0.74$ to 6.36$)$ & 0.161 \\
\hline $40-49$ & & 4.08 (1.72 to 9.69$)$ & 0.001 \\
\hline $50-59$ & & 2.04 (0.94 to 4.43$)$ & 0.073 \\
\hline $60-69$ & & 1.81 (0.86 to 3.83$)$ & 0.118 \\
\hline 70 and older & & 1.00 & \\
\hline Nationality & $\chi^{2}(4)=5.87, p=0.015$ & & \\
\hline Other & & $1.18(0.45$ to 3.12$)$ & 0.743 \\
\hline Other GCC & & $1.40(0.48$ to 4.07$)$ & 0.532 \\
\hline Levant & & 2.20 (0.98 to 4.93$)$ & 0.056 \\
\hline North Africa & & $1.30(0.49$ to 3.44$)$ & 0.597 \\
\hline Qatari & & 1.00 & \\
\hline History & $\chi^{2}(1)=25.14, p<0.001$ & 5.60 (2.92 to 10.77$)$ & $<0.001$ \\
\hline Family history & $\chi^{2}(1)=5.63, p=0.018$ & 2.23 (1.18 to 4.20$)$ & 0.018 \\
\hline Financial stress & $\chi^{2}(1)=6.51, p=0.011$ & 2.01 (1.18 to 3.46$)$ & 0.011 \\
\hline Financial support & $\chi^{2}(4)=14.46, p=0.006$ & & \\
\hline Excellent & & 0.89 (0.27 to 2.95$)$ & 0.845 \\
\hline Good & & $1.00(0.38$ to 2.69$)$ & 0.994 \\
\hline Fair & & 2.39 (0.96 to 5.93$)$ & 0.060 \\
\hline Poor & & 1.01 (0.35 to 2.96$)$ & 0.985 \\
\hline Very poor & & 1.00 & \\
\hline
\end{tabular}

\section{Model summary} -2 Log-likelihood

assistance $(n=31)$, approximately half of them $(n=15)$ described themselves as 'depressed'. Similar to the attitude in many parts of the world, in the Middle East too mental health problems have been stigmatised, and patients have been reported to be very concerned about the damaging consequences and social shame of seeking treatment for themselves or their families. ${ }^{23-25}$ It has been reported that patients are concerned that mental illnesses might hinder their employment/promotion chances, and females often worry that their marital prospects or current marital relationship might be adversely impacted. ${ }^{26}$ It is possible that stigma and anticipated negative social consequences associated with being diagnosed with a mental illness had led to refusal of psychiatric assistance.

In conclusion, depression significantly contributes to the CV mortality and morbidity; to prevent an increase in number of $\mathrm{CV}$ patients with depression, identification of factors that might contribute to psychological disturbances in cardiac patients is necessary. There is a need to raise awareness of mental health issues, and to reduce social stigma that prevent help seeking behaviour so that basic but critical intervention can be implemented to prevent and treat depression in this population. As this study's findings indicate, older Arab women are more likely to develop mood disturbance and depression after being hospitalised with acute cardiac condition. We recommend (1) healthcare providers should be aware of this problem, and integrate gender and age differences approach into their clinical practice; (2) routine systematic screening for depressive symptoms should be conducted with all cardiovascular patients, especially for female in older age groups; and (3) mental health counselling should be available and offered to all cardiovascular patients who exhibit depressive symptoms.

Non-probability convenience sampling limits the ability to generalise the findings from this study. Even though BDI-II has high validity, it might not be accurately able to assess or identify depressive symptoms among Arabic population. However, the information reported in this paper will increase healthcare providers' awareness of depression, and its association with gender and age among Arab cardiac patients in Qatar. The results of this study give insights into the detection of and treatment for depression among Arab cardiac patients that can be applied to patients with similar sociocultural backgrounds throughout the Middle East and globally.

Acknowledgements This publication was made possible by a grant from Qatar National Research Fund under its National Priority Research Programme (NPRP 5-106-3-025). Its contents are solely the responsibility of the authors and do not necessarily represent the official views of Qatar National Research Fund. The authors are grateful to all the patients who participated in this research, as well as to the Qatar National Research Fund which provided us with funding to conduct this study. The authors give their special thanks to staff at the Hamad Medical Corporation (Hamad General Hospital) who helped 
us recruit research participants. The authors thank our project manager IremMueed and research assistants Shima Sharara, Sarah Omar, Noha El Banna and Tamara Marji.

Contributors TTD contributed to the conception and design of the study, and the acquisition, analysis, and interpretation of data; drafted the manuscript; and gave final approval of the manuscript version submitted for publication. JMAS and NA contributed to the conception and design of the study, and the acquisition of data; revised the manuscript; and gave final approval of the manuscript version submitted for publication. AA-Q contributed to the conception and design of the study, and the acquisition of data; reviewed the manuscript critically for content; and gave final approval of the manuscript version submitted for publication. TF contributed to the conception and design of the study, and the acquisition of data; reviewed the manuscript critically for content; revised the manuscript; and gave final approval of the manuscript version submitted for publication. RS contributed to the conception and design of the study, and the acquisition of data; reviewed the manuscript critically for content; and gave final approval of the manuscript version submitted for publication. NAQ contributed to the conception and design of the study, and the acquisition of data; reviewed the manuscript critically for content; and gave final approval of the manuscript version submitted for publication.

Funding This study was made possible by a grant from the Qatar National Research Fund under its National Priorities Research Programme (NPRP 5-106-3-025). Its contents are solely the responsibility of the authors and do not necessarily represent the official views of the Qatar National Research Fund.

Competing interests None declared.

Ethics approval Ethics approval for this research study was obtained from the Hamad Medical Corporation Research Committee (Ethics Approval Reference number RC/59412/2012), the Qatar Supreme Council of Health (Ethics Assurance number SCH-AUCQ-050), and the University of Calgary's Conjoint Health Research Ethics Board (Ethics ID: E-24738).

Provenance and peer review Not commissioned; externally peer reviewed.

Data sharing statement No additional data are available.

Open Access This is an Open Access article distributed in accordance with the Creative Commons Attribution Non Commercial (CC BY-NC 4.0) license, which permits others to distribute, remix, adapt, build upon this work noncommercially, and license their derivative works on different terms, provided the original work is properly cited and the use is non-commercial. See: http:// creativecommons.org/licenses/by-nc/4.0/

\section{REFERENCES}

1. Yusuf S, Reddy S, Ounpuu S, et al. Global burden of cardiovascular diseases: part I: general considerations, the epidemiologic transition, risk factors, and impact of urbanization. Circulation 2001;104:2746-53. 27 November.

2. Gehani AA, Al-Hinai AT, Zubaid M, et al. Association of risk factors with acute myocardial infarction in Middle Eastern countries: the INTERHEART Middle East study. Eur J Prev Cardiol 2014;21:400-10.

3. Awad $\mathrm{HH}$, Zubaid M, Alsheikh-Ali AA, et al. Comparison of characteristics, management practices, and outcomes of patients between the global registry and the gulf registry of acute coronary events. Am J Cardiol 2011;108:1252-8.

4. Baune BT, Stuart M, Gilmour A, et al. Moderators of the relationship between depression and cardiovascular disorders: a systematic review. Gen Hosp Psychiatry 2012;34:478-92.

5. Rutledge T, Reis VA, Linke SE, et al. Depression in heart failure: a meta-analytic review of prevalence, intervention effects, and associations with clinical outcomes. J Am Coll Cardiol 2006;48:1527-37.

6. van Melle JP, de Jonge P, Spijkerman TA, et al. Prognostic association of depression following myocardial infarction with mortality and cardiovascular events: a meta-analysis. Psychosom Med 2004;66:814-22.

7. Donnelly TT, Al Suwaidi J, Alqahtani A, et al. Study exploring depression and cardiovascular diseases amongst Arabic speaking patients living in the State of Qatar: rationale and methodology. Glob Cardiol Sci Prac 2013:56-66.

8. Qatar Statistics Authority, Ministry of Development Planning and Statistics, Population Structure. 2013. http://www.qsa.gov.qa/eng/ population_census/2013/PopulationStructure_Aug.htm.

9. Ceccarini $\bar{M}$, Manzoni GM, Castelnuovo $\mathrm{G}$. Assessing depression in cardiac patients: what measures should be considered? Depress Res Treat 2014;2014:1-17.

10. Abdel-Khalek AM. Internal consistency of an Arabic adaptation of the Beck depression inventory in four Arab countries. Psychol Rep 1998;82:264-6.

11. Donnelly TT, Al Suwaidi JM, Al-Qahtani A, et al. Association between socioeconomic factors and depression among cardiovascular patients living in rich resourced Middle Eastern Country. Int J Cardiol 2016;203:819-21.

12. Celano CM, Huffman JC. Depression and cardiac disease: a review. Cardiol Rev 2011;19:130-42.

13. Carney RM, Freedland KE, Sheline YI, et al. Depression and coronary heart disease: a review for cardiologists. Clin Cardiol 1997;20:196-200.

14. Milani RV, Lavie CJ. Impact of cardiac rehabilitation on depression and its associated mortality. Am J Med 2007;120:799-806.

15. Strik JJ, Honig A, Lousberg R, et al. Sensitivity and specificity of observer and self-report questionnaires in major and minor depression following myocardial infarction. Psychosomatics 2001;42:423-8.

16. Hamdan A, Hawamdeh S, Hussein A. The prevalence and correlates of depressive symptoms among Arab women in a primary health care setting. Int J Psychiatry Med 2008;38:453-67.

17. Hamdan A. Mental health needs of Arab women. Health Care Women Int 2009;30:595-613.

18. Douki S, Zineb SB, Nacef F, et al. Women's mental health in the Muslim world: cultural, religious, and social issues. J Affect Disord 2007;102:177-89.

19. Ringoir L, Pedersen SS, Widdershoven JW, et al. Prevalence of psychological distress in elderly hypertension patients in primary care. Neth Heart J 2014;22:71-6.

20. Eaton WW, Kalaydjian A, Scharfstein DO, et al. Prevalence and incidence of depressive disorder: the Baltimore ECA follow-up, 1981-2004. Acta Psychiatr Scand 2007;116:182-8.

21. Pencina MJ, D'Agostino RB Sr, Larson MG, et al. Predicting the 30-year risk of cardiovascular disease: the Framingham heart study. Circulation 2009;119:3078-84.

22. Ossola P, Paglia F, Pelosi A, et al. Risk factors for incident depression in patients at first acute coronary syndrome. Psychiatry Res 2015;228:448-53.

23. Bener A, Ghuloum S. Ethnic differences in the knowledge, attitude and beliefs towards mental illness in a traditional fast developing country. Psychiatr Danub 2011;23:157-64.

24. Bener A, Ghuloum S. Gender differences in the knowledge, attitude and practice towards mental health illness in a rapidly developing Arab society. Int J Soc Psychiatry 2011;57:480-6.

25. Ghuloum S, Bener A, Burgut FT. Epidemiological survey of knowledge, attitudes, and health literacy concerning mental illness in a national community sample: a global burden. J Prim Care Community Health 2010;1:111-8.

26. Gearing RE, Schwalbe CS, MacKenzie MJ, et al. Adaptation and translation of mental health interventions in Middle Eastern Arab countries: a systematic review of barriers to and strategies for effective treatment implementation. Int $J$ Soc Psychiatry 2013;59:671-81. 